\title{
INTRAMUSCULAR HEMANGIOMA - AN UNUSUAL INJURY OF THE GLUTEUS MUSCULATURE - CASE REPORT
}

\author{
MÁRCIO LUÍS DUARTE'; FERNANDO DA SILVA XAVIER ${ }^{3,4}$; JOSÉ LUIZ MASSON DE ALMEIDA PRADO ${ }^{1,3}$; \\ LUIZ CARLOS DONOSO SCOPPETTA ${ }^{4}$
}

\begin{abstract}
Hemangiomas are benign vascular neoplasms characterized by an abnormal proliferation of blood vessels that most often occur in the skin or subcutaneous tissue, followed by the deep tissues and, occasionally are intramuscular and rarely within a bone. Hemangiomas are the most common benign soft-tissue tumor of infancy and childhood comprising $07 \%$ of all soft tissue tumors. Intramuscular hemangiomas account for $0.8 \%$ of all hemangiomas, growing in size slowly, but never metastasize. Although they affect all age groups, they are more common in young adults and may occur in any muscle. We report the case of a 23-year-old patient with thigh pain for three months.
\end{abstract}

\section{KEYWORDS: HEMANGIOMA; THIGH; MUSCLE, SKELETAL; MAGNETIC RESONANCE IMAGING; ULTRASONOGRAPHY}

\section{INTRODUCTION}

The word hemangioma comes from the Latin words "hemangio" which means blood vessel and "oma" which means tumor with cell division activity. ${ }^{1}$ Hemangiomas are benign vascular neoplasms characterized by an abnormal proliferation of blood vessels that occur most frequently in the skin or in the subcutaneous tissue, followed by deep tissue, and occasionally intramuscularly and rarely within the bones. ${ }^{2-6}$

Hemangiomas are the most common benign soft tissue tumors in childhood, comprising $7 \%$ of all soft tissue tumors. ${ }^{2-6}$ Intramuscular hemangiomas account for $0.8 \%$ of all hemangiomas, growing slowly in size but never metastasizing and despite affecting all age groups, they are more common in young adults and can occur in any muscle., ${ }^{1,-4,6-8}$ Their growth can be accelerated with trauma - 17\% of cases, but they can regress spontaneously. ${ }^{3,4}$ A sudden increase in size when taking oral contraceptive pills has also been reported. ${ }^{4}$ Its malignant transformation is rare and may be accompanied by bone atrophy as well as reactive bone changes. 3,6

Histologically, soft tissue hemangioma can be classified into five types: capillary, cavernous, arteriovenous, venous, and mixed hemangioma., ${ }^{5,6}$ Capillary hemangiomas are more common in muscle than in cavernous and compound types. ${ }^{2}$ The etiology is unclear, but possibly of congenital origin. $^{2,6,8}$

\section{CASE REPORT}

23-year-old woman with pain in her right thigh for three months, without other complaints or other pathologies. On physical examination, the patient has no movement limitations or lameness during gait. Ultrasonography demonstrates a heterogeneous and partially defined nodular formation in the gluteus medius muscle (Figure 1).

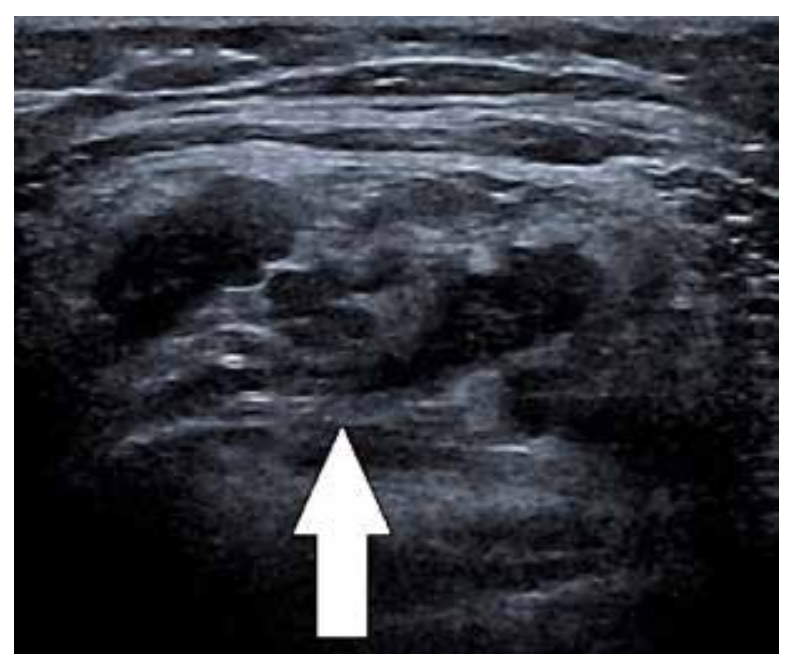

Figure 1: Ultrasonography showing a heterogeneous and partially defined nodular formation in the right gluteus medius muscle (white arrow).
1. Médico radiologista da WEBIMAGEM Telerradiologia, São Paulo-SP, Brasil.

2. Mestre em Saúde Baseada em Evidências pela UNIFESP, São Paulo-SP, Brasil.

3. Médico radiologista do United Health Group, São Paulo-SP, Brasil.

4. Médico radiologista do Hospital São Camilo, São Paulo-SP, Brasil.

\section{MAILING ADDRESS}

MÁRCIO LUÍS DUARTE

Av. Marquês de São Vicente, 446, Barra Funda.

São Paulo - SP. CEP: 01139-020;

E-mail: marcioluisduarte@gmail.com 
Magnetic resonance imaging (MRI) demonstrates irregular intramuscular expansive formation in the right gluteus medius, with mildly high signal on $\mathrm{T} 1$, high heterogeneous signal on $\mathrm{T} 2$ with intense contrast enhancement, compatible with intramuscular hemangioma (Figures 2 and 3 ).
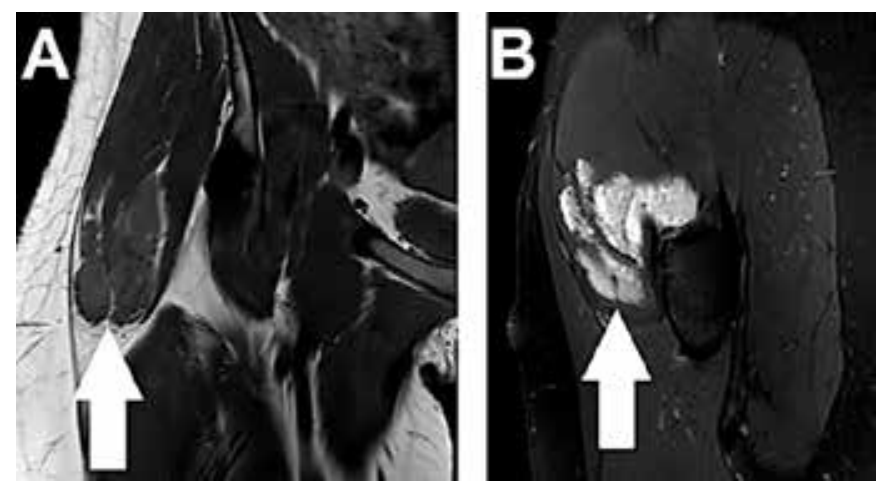

Figure 2: In A, MRI in the coronal section on the $\mathrm{T} 1$ sequence and in $\mathrm{B}$, the MRI in the sagittal section in the T2 SPIR sequence demonstrate irregular intramuscular expansive formation in the right gluteus medius (white arrow).

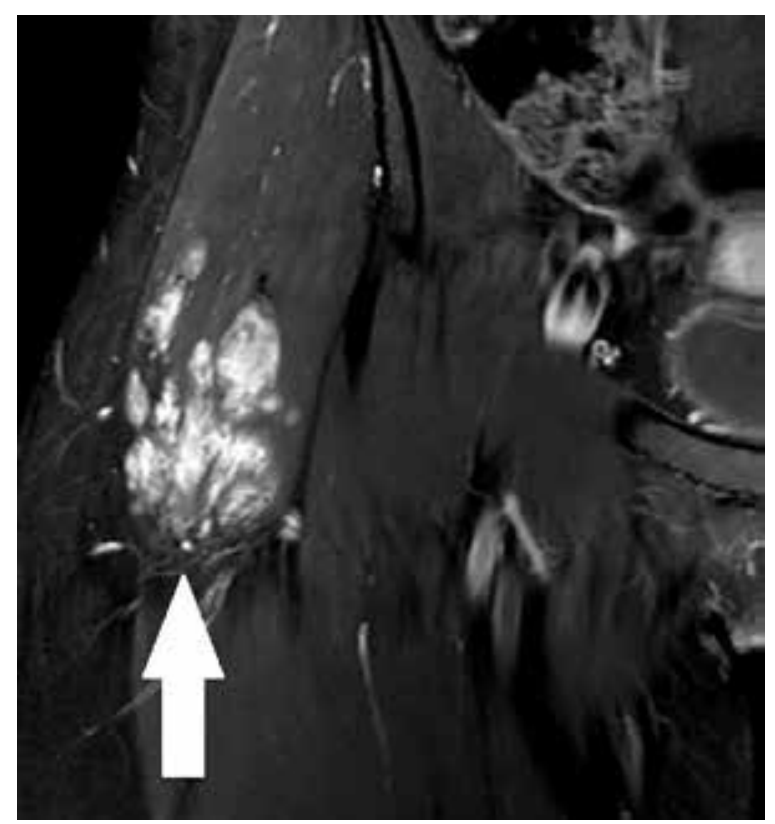

Figure 3: Contrast-enhanced coronal MRI scan on T1 FAT SAT sequence demonstrates irregular intramuscular expansive formation in the right gluteus medius with intense contrast enhancement, compatible with intramuscular hemangioma (white arrow).

\section{DISCUSSION}

It is estimated that $90 \%$ of intramuscular hemangiomas occur before the third decade of life and there is a general consensus that women are more commonly affected than men, and may increase in size during pregnancy. ${ }^{1,2,5-8}$ Tumors they range in size from less than $4 \mathrm{~cm}$ to more than $20 \mathrm{~cm}$, but most are less than $9 \mathrm{~cm}$ in diameter.

Because they are located in the muscle, hemangiomas usually do not present visible signs, although some may cause edema in the tumor area, which increases with activity and may be pulsatile and present a murmur - arteriography is indicated in these cases ${ }^{2-4,8}$ Pain it is a cardinal symptom in $60 \%$ of cases, with the lower limb being the most common site of involvement $(42-45 \%)$, with the quadriceps being the most frequently affected muscle. ${ }^{1-3,8}$

Patients usually present with an elevated tumor with 50 to $60 \%$ pain, along with symptoms of pressure ${ }^{1,2}$ Complications of hemangioma include functional impairment, necrosis of overlying skin, bone erosion, entrapment of vessels and nerves, heart failure, thrombocytopenia and consumptive coagulopathy (Kasabach-Merritt syndrome).8 Hemangiomas are diagnosed by physical examination, plain radiographs, Doppler ultrasound and MRI.,

Plain radiography may show foci of calcification - 25\% of cases, which are highly suggestive of hemangioma. ${ }^{2,3,8}$ The Swiss cheese pattern of ossification is seen as ill-defined ossification with coarse trabecular pattern on plain radiographs, whereas phlebolite presents hyperdensity round or well-defined oval, characteristically with central lucent. ${ }^{7}$ Angiography is useful to delineate if there is a nourishing vessel that can be embolized. ${ }^{3}$

In intramuscular hemangiomas, color Doppler ultrasonography is useful exclusively to demonstrate vascular structures around the muscle and to assess pathological changes such as fibrosis and to detect calcifications.4 Color Doppler ultrasonography demonstrates a well-defined hypoechoic mass with heterogeneous echotexture. ${ }^{4}$

An MRI is important for the characterization and extension of soft tissue hemangioma and is the method of choice. 3,6,8 On T1-weighted images, the hemangioma has a low to intermediate signal intensity mass, with high signal intensity peripheral due to fat.2,4,8 On T2-weighted images, it presents areas of high signal due to vascular tissue and intermediate signal intensity due to fat.2,4,8 Contrast-enhanced MRI shows serpentine enhancement of lesions. ${ }^{5,7}$ The presence of lobulation, septation, and nodular hypointense foci on T2-weighted images facilitates diagnosis.6 As imaging is often diagnostic for soft tissue hemangiomas, biopsy is not necessary. ${ }^{5}$

The treatment of choice is complete excision of the lesion. 4 There is a recurrence rate of $9-28 \%$ after surgical excision.2,4 Sclerotherapy has a role in the management of intramuscular hemangioma when excision is not possible. 4

\section{CONCLUSION}

Patients with palpable masses on physical examination require further investigation for diagnosis. In these cases, the hemangioma must be remembered and investigated, because the biopsy can cause extensive bleeding and the diagnosis can be made only with imaging exams. 


\section{REFERENCES}

1. Shah SA, Hassan F. Intramuscular haemangioma of the triceps muscle. Journal of Surgery Pakistan (International) 2012;17(1):40-42.

2. Rai HR, Ballal A, Mohan K, Rajsankar NR. Cavernous haemangioma in the gastrocnemius muscle: a rare presentation in the geriatric age group. NUJHS 2014;4(3): 101-104.

3. Wani IH, Bhat MS, Basit S, Khursheed O, Jan M, Kawoosa SS. Intramuscular haemangioma of vastus lateralis presenting as stiffness of knee in an adolescent patient. OA Orthopaedics 2014;18;2(1):2.

4. Lakshmi KC, Sankarapandiyan S, Mohanarangam VSP. Intramuscular haemangioma with diagnostic challenge: a cause for strange pain in the masseter muscle. Case Rep Dent. 2014;2014: 285834.

5. Olsen KI, Stacy GS, Montag A. Soft-tissue cavernous hemangioma. RadioGraphics 2004; 24:849-854.

6. Pourbagher A, Pourbagher MA, Karan B, Ozloc G. MRI manifestations of soft-tissue haemangiomas and accompanying reactive bone changes. Br J Radiol. 2011; 84(1008):1100-1108.

7. Jin W, Kim GY, Lee JH, Yang DM, Kim HC, Park JS, Ryu KN. Intramuscular hemangioma with ossification emphasis on sonographic findings. J Ultrasound Med 2008; 27:281-285.

8. Kiran KR, Babu TVS, Babu SS, Deepti K. Skeletal Muscle Haemangioma: a cause for chronic pain about the knee: a case report. Case Rep Orthop. 2012;2012: 452651. 